\title{
O Ensino da Adição e Subtração de Arcos Trigonométricos, através da Música: Um Relato de Prática
}

\section{Renata Aparecida Pereira Teodoro}

\section{Resumo e Objetivos da Aula}

O conteúdo matemático vem sempre acompanhado de muitas fórmulas, sendo algumas imprescindíveis a memorização para resolução das atividades propostas, a ausência de conhecimento destas, dificulta a aprendizagem, pois acarreta erros, principalmente na adição e subtração de arcos. As fórmulas, vistas sem contextualização não tem significado algum para o aluno. Diante disso o principal objetivo da aula foi aprender de forma divertida a memorizar a fórmula da adição e subtração de arcos através de música. Assim a aula de Matemática saiu do tradicional sendo mais interativa e dinâmica, a aprendizagem mais significativa.

Palavras chave: Ensino de Trigonometria, Fórmulas, Música 


\section{Temática da Aula: Adição e Subtração de Arcos}

A Matemática é uma disciplina considerada por muitos como difícil. É notória em sala de aula, a resistência que os alunos têm isso devido ao certo grau de abstração e descontextualização que os conteúdos e os conceitos da matéria são apresentados a eles.

"A estrutura formal da Matemática exige, em algum momento, um refinamento preciso dos conceitos, como ocorre em qualquer ciência que faz uso da linguagem técnica" (QUINTANEIRO 2010, p.04). Números são sinônimos de Matemática, eles são fundamentais, mas para uma melhor compreensão é essencial compreender conceitos, e estes vem acompanhados por uma linguagem técnica, conhecido como fórmulas Matemáticas. Tall e Vinner comentam:

"Comparado com outras áreas de empreitada humana, Matemática é usualmente considerada como uma matéria de muita precisão em que conceitos podem ser definidos seguramente para fornecer uma fundação firme para a teoria matemática. As realidades psicológicas são sutilmente diferentes.” (TALL, VINNER 1981, pg 151, tradução da autora)

A trigonometria (trigono: triângulo e metria: medidas) é um campo da Matemática que estuda proporção, fixa dos lados de um triângulo retângulo, para diversos valores de um dos seus ângulos agudos, principalmente os ângulos notáveis $\left(30^{\circ}, 45^{\circ}\right.$ e $\left.60^{\circ}\right)$. Sendo este um setor da Matemática que os alunos possuem grande dificuldade.

Alguns conceitos básicos, como seno, cosseno e tangente, são introduzidos no ensino fundamental e no ensino médio estes são aprofundados em forma de função. Para isto é necessário compreender primeiramente os conceitos acerca da trigonometria, tais quais, os de ciclo trigonométrico, ângulos e radianos, quadrante, arcos, radianos e arcos côngruos.

Um arco é uma porção compreendida entre dois entre extremos de uma curva, possui um ângulo interno e dependendo do quadrante em que se encontra a função seno, cosseno ou tangente, assume valor positivo ou negativo.

Na trigonometria, para achar o valor de um respectivo arco, precisamos encontrar o arco côngruo do primeiro quadrante e sinal que o valor do arco assume é o do quadrante em que se encontra.

Por exemplo, determinar o valor da função seno e cosseno do $\operatorname{arco} 210^{\circ}$. O arco de $210^{\circ}$, encontra-se no terceiro quadrante do ciclo trigonométrico, e este é côngruo ao ângulo notável $30^{\circ}$, o que significa que este possui o mesmo valor que o seu respectivo ângulo notável correspondente no primeiro quadrante, mas o assume o sinal do terceiro quadrante, ou seja, sen $=-\frac{1}{2}$ e $\cos =-\frac{\sqrt{3}}{2}$. Como o arco de $210^{\circ}$ está no terceiro quadrante e no 
terceiro quadrante os valores da função seno e cosseno, são sempre negativos, logo este assume também valor negativo.

Uma volta completa no ciclo trigonométrico corresponde a $360^{\circ}$. Logo, quando um arco é maior que $360^{\circ}$, quer dizer que o arco possui mais de uma volta. Assim, primeiro precisa-se saber quantas voltas ele tem e ver onde o arco irá parar. Para isso, é necessário dividir o valor do arco por $360^{\circ}$.

Por exemplo, determinar a função seno do arco de $1320^{\circ}$. Logo ao dividir $1320^{\circ}$ por $360^{\circ}$, conclui-se que este arco possui três voltas completas e para em $240^{\circ}$. Depois se encontra o côngruo, correspondente deste arco no primeiro quadrante e analisa o sinal do terceiro quadrante, logo o seno de $1320^{\circ}$ é igual $-\frac{\sqrt{3}}{2}$, pois seu valor corresponde ao arco de $60^{\circ}$

Em alguns casos, porém, não se consegue encontrar o valor das funções seno, cosseno e tangente conforme os exemplos anteriores, pois alguns não possuem um côngruo correspondente. Diante destes arcos, tais como, o arco de $15^{\circ}, 75^{\circ}$ e $105^{\circ}$, por exemplo, para encontrar as funções trigonométricas, é necessário pensar como escrever este número de outra forma, conforme ilustra a Tabela 1 a seguir:

Tabela1: Arco de $15^{\circ}, 75^{\circ}$ e $105^{\circ}$

\begin{tabular}{|c|}
\hline $15^{\mathrm{o}}=45^{\mathrm{o}}-30^{\mathrm{o}}$ \\
\hline $75^{\mathrm{o}}=30^{\mathrm{o}}+45^{\mathrm{o}}$ \\
\hline $105^{\mathrm{o}}=60^{\mathrm{o}}+45^{\mathrm{o}}$ \\
\hline Criação da autora
\end{tabular}

Para encontrar os valores das funções trigonométricas destes arcos é necessário então somar e/ou subtrair os valores que correspondem o arco. Seno fundamental a compreensão e a utilização de algumas fórmulas de soma e subtração de arcos.

A seguir, seguem as respectivas fórmulas da adição e subtração de arcos na função seno, cosseno e tangente. 
Tabela 2: Fórmulas da Adição e Subtração

\begin{tabular}{|l|}
\hline $\operatorname{sen}(a+b)=\operatorname{sen} a \cdot \cos b+\operatorname{sen} b \cdot \cos a$ \\
\hline $\operatorname{sen}(a-b)=\operatorname{sen} a \cdot \cos b-\operatorname{sen} b \cdot \cos a$ \\
$\cos (a+b)=\cos a \cdot \cos b-\operatorname{sen} a \cdot \operatorname{sen} b$ \\
$\cos (a-b)=\cos a \cdot \cos b+\operatorname{sen} a \cdot \operatorname{sen} b$ \\
$\operatorname{tg}(a+b)=\frac{\operatorname{tg} a+\operatorname{tg} b}{1-\operatorname{tg} a \cdot \operatorname{tg} b}$ \\
$\operatorname{tg}(a-b)=\frac{\operatorname{tg} a-\operatorname{tg} b}{1+\operatorname{tg} a \cdot \operatorname{tg} b}$ \\
\hline $\operatorname{Criação~da~autora~}$ \\
\hline
\end{tabular}

Quando os alunos observaram o quadro, com as fórmulas acima descritas, eles ficaram assustados, pensando em como aplicá-las e memorizá-las.

Diante disso, ao ensinar a soma e subtração de arcos, para os alunos da $2^{\text {a }}$ Série do Ensino Médio da Escola Estadual Maurílio Albanese Novais, em 2015, apresentei a eles além dos conceitos e fórmulas de adição e subtração de arcos, ensinei-os uma "musiquinha", para os discentes memorizarem as fórmulas.

Abaixo a letra da música, esta não possui uma melodia específica, pois foi uma ideia divertida que tive ao ensinar o conteúdo para os adolescentes do Ensino Médio do Albanese.

SeCo, SeCo ... Mantém o sinal!

CoCo , Se Se... Troca o sinal!

Tem Gente que Ama, Tem Gente que Beija.... Huuuuum, Tem Gente que Ama e Beija.

A primeira notação musical se refere a fórmula de soma e subtração da função seno, em que se permanece o sinal central igual ao principal da operação. A segunda notação se refere a fórmula da adição e subtração da função cosseno, onde acontece a troca de sinal, ou seja, se estou somando, o sinal central será negativo, e vice versa. Quando me refiro à função tangente, digo "Tem Gente”, “Ama” e "Beija” se refere aos valores diferentes dos números, "Huuuumm" ao número um do denominador da fórmula, "Tem Gente que Ama e Beija", refere-se à multiplicação das tangentes dos números diferentes. 
Deste modo, nas atividades propostas, que pedia para determinar os valores de seno, cosseno e/ou tangente de $15^{\circ}, 75^{\circ}$ e $105^{\circ}$, a resolução será através da utilização das formulas acima descrita. Conforme os exemplos resolvidos abaixo, de algumas das atividades realizadas:

$$
\begin{aligned}
& \text { Ex. (1) Sen } 15^{\circ}=\left(\operatorname{sen} 45^{\circ}-30^{\circ}\right) \\
& \operatorname{sen} 45^{\circ} \cdot \cos 30^{\circ}-\operatorname{sen} 30^{\circ} \cdot \cos 45^{\circ}= \\
& \frac{\sqrt{2}}{2} \cdot \frac{\sqrt{3}}{2}-\frac{1}{2} \cdot \frac{\sqrt{2}}{2}= \\
& \frac{\sqrt{6}}{4}-\frac{\sqrt{2}}{4}= \\
& =\frac{\sqrt{6}-\sqrt{2}}{4}= \\
& \operatorname{Ex}(2) \operatorname{Cos} 75^{\circ}=\left(\cos 30^{\circ}+45^{\circ}\right) \\
& \cos 30^{\circ} \cdot \cos 45^{\circ}-\operatorname{sen} 30^{\circ} \cdot \operatorname{sen} 45^{\circ}= \\
& \frac{\sqrt{3}}{2} \cdot \frac{\sqrt{2}}{2}-\frac{1}{2} \cdot \frac{\sqrt{2}}{2}= \\
& \frac{\sqrt{6}}{4}-\frac{\sqrt{2}}{4}= \\
& =\frac{\sqrt{6}-\sqrt{2}}{4}= \\
& \operatorname{Ex}(3) \operatorname{tg} 105^{\circ}=\operatorname{tg}\left(60^{\circ}+45^{\circ}\right) \\
& \frac{\operatorname{tg} 60^{\circ}+\operatorname{tg} 45^{\circ}}{1-\operatorname{tg} 60^{\circ} \cdot \operatorname{tg} 45^{\circ}}= \\
& \frac{\sqrt{3}+1}{1-\sqrt{3.1}}= \\
& \frac{\sqrt{3}+1}{1-\sqrt{3}} \cdot \frac{1+\sqrt{3}}{1+\sqrt{3}}= \\
& \frac{\sqrt{3}+3+1+\sqrt{3}}{1+\sqrt{3}-\sqrt{3}-3}= \\
& \frac{4+2 \sqrt{3}}{-2}= \\
& \frac{2(2+\sqrt{3})}{-2}= \\
& -1(2+\sqrt{3})= \\
& =-2-\sqrt{3}
\end{aligned}
$$

ISSN 2526-2882

$$
\text { *** }
$$


O valor da função seno do arco de $15^{\circ}$ é igual ao valor da função cosseno do arco de $75^{\circ}$. Logo correspondente a uma determinada função de um arco, pode ser igual a outra função de outro arco. Considerando uma função seno a ser determinado, caso o aluno faça a soma ou a subtração para o mesmo arco, o valor encontrado será o mesmo tanto adição quanto na subtração, e assim sucessivamente para as demais funções trigonométricas.

A "musiquinha" gravou na mente dos alunos, de tal forma que estes quando me viam, já gostavam de cantar a música, pois assim conseguiram memorizar as fórmulas sem muita dificuldade. Após a explicação dinâmica e criativa do conteúdo, os alunos realizaram atividades sobre o tema estudado a fim de adquirir uma aprendizagem significativa.

\section{Procedimentos}

- Foi realizada uma aula expositiva, onde os conteúdos de soma e subtração de arcos foram abordados.

- Apresentação de uma música a fim de fazer os discentes compreender através de um hit musical a matéria com mais facilidade.

- Exercícios sobre soma e subtração de arcos das funções seno, cosseno e tangente.

\section{Conteúdos}

O conteúdo abordado foi adição e subtração de arcos das funções seno, cosseno e tangente. A aula foi realizada nas turmas da $2^{\mathrm{a}}$ Série do Ensino Médio, na Escola Estadual Maurílio Albanese Novais, em Ipatinga, Minas Gerais em 2015.

\section{Reflexões}

Atualmente a Matemática tradicional, já não é o suficiente para ensinar os alunos da contemporaneidade. O estudante hoje espera mais que o tradicional livro, quadro e giz. Estes recursos são necessários, mas é essencial que o professor busque novas métodos para ensinar.

Alguns analisam como Chervel, a escola um ambiente de rotinas:

A concepção da escola como puro e simples agente de transmissão de saberes elaborados fora dela está na origem da idéia, muito amplamente partilhada no mundo das ciências humanas e entre o grande público, segundo a qual ela é, por excelência, o lugar do conservadorismo, da inércia, da rotina. Por mais que se esforce, raramente pode-se vê-la seguir, etapa por etapa, nos seus ensinos, o progresso das ciências que se supõe ela deva difundir (CHERVEL, 1990, p.182). 
Para Sobreira (2012, p.123) apud (JULIA, 2001; FORQUIN, 1993; LOPES, 1999, 2002, 2008) "concebem a escola como instituição criadora de uma cultura específica que deve ser compreendida em outros termos".

Para Teodoro (2015, p. 8) "o perfil profissional que sociedade almeja hoje privilegia a criatividade e capacidade de interagir com os alunos", diante desta tarefa, a inclusão da música na aula de Matemática, trouxe consigo a interatividade e a construção do conhecimento.

Buscar novas metodologias para ensinar e interagir com o aluno, tornar a aula de Matemática divertida e prazerosa é o desafio do professor da atualidade. Percebe-se que há uma grande resistência do professor com o novo, pois, o novo causa sempre um desconforto, sendo este primeiro a ter que se adaptar.

Cabe ao professor aprender para ensinar, pois os mesmos, estão adaptados e acomodados ao mesmo método que ensinavam a alguns anos atrás. O tempo passando, muitas coisas se modificam, por exemplo, há quinze anos, não havia a mesma quantidade de alunos que temos hoje como celular em mãos. Sendo este resultado da proliferação dos dispositivos de comunicação em massa.

Por consequência, o professor tende analisar as influências socioculturais, religiosas, em que o aluno, personagem principal no contexto educacional é envolvido, e buscar diariamente criar um novo método de ensinar o mesmo conteúdo que já ensina há tempo. Para Amaral e Garbin (2008), o ambiente escolar representa, neste início de século, um fator de diferenciação social e de necessidade de vida, pois nele se buscam informação e formação.

"O educando, até pela sua condição de aprendiz, está sempre em busca de novidades e o professor pode aproveitar situações cotidianas para melhorar a qualidade de suas aulas" (OLIVEIRA et al, 2011, p.232). O discente da atualidade aprecia tecnologia, música e jogos. Em outras palavras, a interação e a criatividade, ingredientes estes, que levam ao conhecimento significativo.

Nessa perspectiva, a música está presente no dia-a-dia da juventude, sendo algo que os jovens apreciam, ainda que pouco explorada como Oliveira et al(2011), pode ser uma ferramenta utilizada para ensinar conteúdos.

Diante disso, ao introduzir adição e subtração de arcos, apresentei-os uma "musiquinha", que a princípio para eles acharam engraçada, não levaram muito a sério, mas depois, ao ver a real aplicação, que com esta forma divertida de associar a música ao conteúdo matemático, eles conseguiram aprender com mais simplicidade, eles acharam sensacional. 
"O uso dessas ferramentas pode inovar a práxis pedagógica e aproximar conceitos científicos ao cotidiano do estudante, além de transformar e dinamizar o ambiente escolar" (OLIVEIRA et al, 2011, p.233).

Através da música foi possível inter-relacionar-se com todos os alunos, logo assim que a música foi apresentada, todos a cantavam. E a "musiquinha” de somar e subtrair arcos virou hit durante a aula de Matemática.

A aula de Matemática neste dia, foi fantástica, era possível ouvir dos alunos, após a aula, alguns comentários, tais como, "melhor aula de Matemática da minha vida", "foi muito legal”, “ eu não vou me esquecer mais”.

Desta forma, percebe-se, o quanto é importante buscar novas formas de ensinar, práticas pedagógicas diferentes, fazem a diferença na sala. A satisfação dos alunos foi grandiosa, pois estes não estavam acostumados a aprender Matemática de uma forma tão divertida e dinâmica. E eu fiquei com a sensação de dever cumprido.

Compete ao professor proporcionar ao aluno, aprendizagem dinâmica, criativa e interativa. Somente assim o aprendiz terá o entusiasmo para ir à escola, e pensar "hoje tem aula de Matemática, que bom” e não "mas que aula chata”.

Logo após a apresentação e explicação do conteúdo, as atividades ficaram bem mais simples de se realizar, era só lembrar-se da "musiquinha". O rendimento da aula foi muito bom, pois os alunos ficaram empolgados com a matéria.

A experiência citada acima contribuiu de forma positiva para o aprendizado dos alunos. A Matemática é uma ciência em que é necessário compreender conceitos e aprender fórmulas, sendo estas com aplicações fundamentais. Diante disso, o professor tende a inventar e reinventar diariamente um novo método para a aprendizagem ser eficaz e eficiente.

\section{Referências}

AMARAL, S. F.; GARBIN, M. C. Construção de um ambiente educacional interativo na internet: a Biblioteca Escolar Digital. Revista Ibero-americana de Educación, v. 45, n. 6, p. 1-11, abr. 2008. Disponível em: < http:// www.rieoei.org/expe/2378Amaral.pdf>Acesso em 06 de maio 2016.

CHERVEL, André. História das Disciplinas Escolares: reflexões sobre um campo de pesquisa. Teoria e Educação, n.2. 1990, p.177-229.

Oliveira, Adriane Dall'Acqua de et al. Interação Entre Música e Tecnologia Para o Ensino de Biologia: Uma Experiência Utilizando a Web-Rádio. Ens. Pesqui. Educ. Ciênc. (Belo Horizonte), Dez 2011, vol.13, no .3, p.231-241. ISSN 19832117 
QUINTANEIRO, Wellerson. Representações e Definições Formais em Trigonometria no Ensino Médio. Dissertação de Mestrado apresentada na UFRJ. 2010.

SOBREIRA, Silvia. A Disciplinarização do Ensino de Música e as Contingências do Meio Escolar. Per musi, Dez 2012, no.26, p.121-127. ISSN 1517-7599.

TALL, D., VINNER, S. Imagem de Conceito e Definição de conceito em Matemática, com especial referência em Limites e Continuidades. Educational Studies in Mathematics, 12, pp. $151-169,1981$.

Biografia Resumida

Renata Aparecida Pereira Teodoro: Graduada em Matemática pela Faculdade de Ciências Gerenciais de Manhuaçu- FACIG, especialista em Matemática Financeira e Estatística pela Universidade Cândido Mendes - UCAM.

Link do lattes: http://lattes.cnpq.br/4673530606022437

e-mail: renatinhapereira18@hotmail.com 